\title{
Family Attitudes and Gender Role Divisions of Married Women in Contemporary Vietnam and Korea ${ }^{\dagger}$
}

This study attempts to examine family attitudes and gender role divisions of married women in contemporary Vietnam and Korea. Drawing data from the 2003 Vietnam Family Study and the 2005 Korean Marriage and Fertility Study, this study investigated 1) attitudes of married women toward marriage, cohabitation, divorce, and having children, 2) decision making on household expenditures, and 3) household work division between husband and wife. The results showed that married Korean women were less inclined toward traditional family attitudes regarding marriage and children than married Vietnamese women. Decision on routine household expenditures was made and household work was done mostly by the wife in the two countries. In comparison, married Vietnamese men took more responsibilities for important financial decisions and child education than married Korean men. These overall findings imply that patriarchical family and gender role norms were preserved to larger extent in contemporary Vietnam than in Korea.

One of the recent trends in Korean marriage statistics is a drastic increase in intercultural marriages between Korean men and foreign women. While the nationalities of the foreign women are diverse, the majority of the women have come from Asian countries, especially from China or Vietnam.

\footnotetext{
${ }^{\dagger}$ This study is supported by Research Abroad Grant of LG Yonam Foundation.

Associate Professor, Department of Child Development \& Family Studies, Seoul National University (mchin@snu.ac.kr)

Key Words: decision-making, family attitudes, gender role, household work, Korea, Vietnam
}

Following China, Vietnam has sent the second largest number of women to Korea during the last ten years ${ }^{1}$. The number of intercultural marriages between Korean men and Vietnamese women rose from 77 in 2000 to 9,623 in 2010 (Korean Statistics Office, 2011). This figure accounts for 2.9 percent of all marriages and 36.6 percent of all intercultural marriages in 2010. It is less clear, however, why Vietnam sent a larger number of women to Korea compared to other Asian countries or why Korea accepted more Vietnamese women than women of other nationalities. Surely, one explanation is the discrepancy in economic development between the two countries. Because many foreign wives cross the border for economic reasons (Piper, 2003), employment opportunities in Korea are a pulling factor from the perspective of Vietnamese women. However, the draw of potential jobs still does not explain why Korea accepted more Vietnamese women than women from other Asian countries of similar economic development level, such as Indonesia or the Philippines.

To understand this large entry of Vietnamese women, we need to pay attention to social and cultural aspects as well as economic aspects of the two countries. Vietnam has long been under the influence of Chinese culture. Vietnam and Korea,

\footnotetext{
'Chinese women made up the largest proportion with $36.6 \%$ of all intercultural marriages in 2010 (Korean Statistics Office, 2011). China, a country adjacent to Korea, has had significant cultural influence on Korea throughout Korea's history. A Korean-origin minority population exists in China, and approximately fifty percent of the wives from China were members of the Korean-origin minority population. Thus, they could speak the Korean language and had some familiarity with Korean culture.
} 
under the influence of Chinese Confucianism, are thus considered to have similar cultural norms in terms of family and gender roles. It is commonly believed that Korean men prefer Vietnamese women as marital partners for these reasons and expect them to adjust quickly to Korean family values and norms. However, little empirical research has yet examined cultural norms on family and gender roles among contemporary Vietnamese. Most of the literature on Vietnamese families has focused on precolonial Vietnamese families in terms of Confucian influence (e.g., Whitmore, 1984; Yu, 1997). Furthermore, it is even rarer how cultural norms of family and gender roles in Vietnam and Korea are similar or dissimilar. Because little empirical research has been done on contemporary Vietnamese and Korean families, this study attempts to fill the gap by making a cross-cultural comparison.

The purpose of this study is to compare the contemporary family norms of the two countries descriptively. Since family norms is too broad a concept, this study focuses on family attitudes and gender role divisions within the family. Family attitudes and gender role divisions within the family show how people view family and how people fill family roles. Family attitudes refer to personalized value orientations and reflect general social norms regarding family. Family attitudes are associated with more concrete social entities and less abstract and durable than family values (Lee, Katras, \& Bauer, 2010). Gender role divisions within the family are manifested in the process of housework division and decision-making about finances between husbands and wives. Asking questions to married women in both countries, this study specifically compares (a) how attitudes toward marriage, cohabitation, divorce, and having children differ between the two countries, and (b) how financial management and household work are arranged between husbands and wives in each country.

This study is mainly exploratory and descriptive because of the paucity of previous literature and data limitation. When a cross-cultural approach is taken, Korean families are often compared with East Asian countries such as China and Japan. It is only very recent that Korean scholars have been interested in
Southeast Asian cultures. Another limitation comes from the lack of data. There is no data set available that has compared family attitudes and gender roles in both countries with exactly the same survey questions. This study uses two different data sets that contain comparable survey questions. Because the wordings of the questions are not identical, pooling data may lead to measurement errors. The findings should, therefore, be interpreted as exploratory. Notwithstanding, with the increase in intercultural marriages and with a shifted focus of interest to Southeast Asian countries, a cross-cultural study between contemporary Korean and Vietnamese families will contribute to family studies literature by highlighting the similarities and differences between the two cultures. Such information will expand our understanding on contemporary Vietnamese families.

\section{Demographic Portraits of Vietnamese and Korean Families $^{2}$}

General demographic profiles of the two countries provide a starting point to compare the families in the two countries. Vietnam is a young, populous country $^{3}$. The population of Vietnam was $89,029,000$ in 2009. Approximately $35.2 \%$ of the entire population was under the age of 20 in 2008 . In comparison, the population of Korea was 47,041,000 and $25.7 \%$ of the population was under the age of 20 in 2008. In terms of population size, Vietnam is approximately two times larger than Korea.

Vietnam and Korea are both countries with rapidly declining birth rates. In Vietnam, the total fertility rate (TFR) dropped from 2.68 in 1994 to 2.09 in 2005, and to 1.93 in 2010 (UNPD_ WFD_2008 Period Fertility Indicators, 2010). The change in TFR is more drastic in Korea. The TFR in Korea dropped from 1.65 in 1995 to 1.08 in 2005, and slightly rose to 1.23 in 2010 (Korean Statistics Office, 2011). While the TFR of Vietnam is higher

\footnotetext{
${ }^{2}$ All the statistics for Vietnam in this section are the most recent ones available at the time of this study. The Korean statistics are selected purposely on the basis of comparability in terms of the years.

${ }^{3}$ Vietnam is a large country with significant political-economic and cultural difference between the South and the North. However, this paper was not able to take this into account due to the availability of data.
} 
than that of Korea, the TFR of Vietnam is considerably below the average observed for lowincome countries (Nguyen-Dinh, 1997).

Marriage and divorce statistics imply the prevalence and stability of family formation and dissolution. The crude marriage rate of Vietnam was 6.4 in 2004 and 5.7 in 2007. The crude marriage rate of Korea was 6.4 in 2004 and 7.0 in 2007. The crude divorce rate of Vietnam was 0.2 in 2004 and 0.2 in 2007. The crude divorce rate of Korea was 2.0 in 2004 and 2.5 in 2007 (UN Statistics Division, Demographic Yearbook 2008). The marriage rates of the two countries are similar, but the divorce rates are ten times higher in Korea. Marriage is still regarded a normative way of partnership formation in both countries. However, divorce seems more acceptable in Korea. There are no nationally representative statistics for household size for Vietnam. Hirshman and Loi (1996) found that the average household size was $4.4 \sim 6.0$ persons; they also found that the average household size was larger in the South than in the North based on the 1991 Vietnam Life History Survey. This average household size was relatively larger than that of Korea: the average household size in Korea was 3.7 persons in 1990 and 3.3 persons in 1995 (Kim, 2002). Although both countries had a traditional norm of living with extended family members, the nuclear family was the most frequently found form of family in both countries.

\section{Traditional Family and Gender Norms in Vietnam and Korea}

Korea and Vietnam have long been influenced by China throughout history. It is often believed that Chinese Confucianism has deeply affected the social organization and culture of the two countries. For this reason, scholars argue that Vietnam belongs to Southeast Asia geographically but is culturally closer to East Asia (Belanger, Oanh, Jianye, Thuy, \& Thank, 2003).

Korea is typical of the East Asian countries which have developed and preserved the Confucian ideology in their family system, moral philosophy, and value system (Lee, 1997). The Confucian ideology is characterized by strong patriarchal principles which include filial piety, father/male dominance, patrilineal succession, and clan organization. These principles separate and govern family members according to gender and generation (Lee, 1997). However, during the last several decades, contemporary Korean families have undergone many changes. Simply put, modern Koreans, like other East Asians, have commonly led family-centered lives, but this modern attribute is becoming increasingly untenable due to the various structural conditions of East Asian modernity and late modernity (Chang, 2010) ${ }^{4}$.

A common image of Vietnam is also pictured with respect to Chinese culture. Vietnam has been often portrayed as a country modeled after its northern neighbor due to the thousand years of Chinese domination. The Le dynasty from 1428 to 1788 actively utilized Confucian morals and principles to govern the nation (Whitmore, 1984). Chinese influence was found in a major law code of Vietnam in the pre-colonial period. The National Penal Code (Quoc Trieu Hinh Luat known as Le Code) resembled the Chinese Penal Codes (known as Tang Code established and used during the Tang Dynasty) to some extent. For example, the National Penal Code manifested the superiority and authority of the household head over his wife and children and the subordinate status of women (Yu, 1997). The patriarchal family served as the basic social institution, with Confucianism framing the social norms in terms of the duties and obligations of family members. Ancestor worship, a strong preference for sons, and arranged marriage resulted from the Confucian norms.

However, scholars argued that Chinese Confucian culture had not penetrated the lives of the general population in pre-colonial Vietnam (Bryant, 2002; Hirschman \& Loi, 1996; Whitmore, 1984). The Le Code accepted the right of women to divorce, allowed equal inheritance among sons and daughters, and mentioned separate finances between the husband and wife, reflecting indigenous Vietnamese

\footnotetext{
${ }^{4}$ East Asian countries compressively experienced modernization within a very short time period compared to Western countries and have been exposed to different economic structures, social relations, and cultural environments depending on different times of birth and other social factors (Chang, 2010).
} 
norms. These features resembled those of Southeast Asian culture, which reflected women-oriented Asian culture, bilateral family lineage, and gender equality. Consequently, women had higher status in Vietnam than in China during the pre-colonial and colonial periods (Belanger et al., 2003; Jayakody \& Huy, 2008; Yu, 1997).

Vietnam has experienced many significant historical events in the twentieth century: the end of French colonization in 1954, the war fought against the United States and reunification into a socialist state in 1975, and an official adoption of market economy in 1986 (Doi Moi). These historical events have influenced Vietnamese families and cultures, particularly in the North, where traditional ideas were challenged by party doctrine, the demands of war, collectivization, war effort, and the increased movement of women into the labor force (Jayakody \& Huy, 2008).

Based on previous researches, we expect that some similarities in family values and norms exist between Korea and Vietnam. However, we expect some differences as well. As many have argued, simple understanding with too much attention paid to Confucian influence can mask the diverse features of each country. Therefore, this study tries to examine the similarities and differences between the two countries. No direct comparison of families based on empirical data has yet been made. It will be an important endeavor to provide empirical information on families in the two cultures.

\section{METHOD}

\section{Data}

Data were drawn from two sources. Information on Vietnamese families was drawn from the 2003 Vietnam Family Study, and information on Korean marriage was drawn from the 2005 Korean National Marriage and Fertility Study. While it is important to synchronize the time period of the point of comparison, no data conducted in more recent years on Vietnamese families was available.

The 2003 Vietnam Family Study was a collaborative project between the Institute of
Sociology in Hanoi, Vietnam and the Population Studies Center at the University of Michigan, US. This project aimed to investigate general family changes in Vietnam and compared men and women of three marriage cohorts: the War cohort, the Reunification cohort, and the Renovation cohort. Among the three cohorts, this study used data of married women of the most recent marriage cohort: the Renovation cohort including those who married between 1992 and $2000(\mathrm{~N}=433)$. While it would be a better approach to draw responses from both men and women, this study used women data because the comparable Korean data contained married women only.

The Korean National Marriage and Fertility Study was a trend study initiated in 2005 and collected every five years. The Korean National Marriage and Fertility Study consisted of two parts: the first part was a survey of unmarried men and women aged 25-45, and the second part was a survey of married women aged 20-45. While there were 2005 and 2009 data waves available at the time of this study, I selected the 2005 data to minimize the time difference from the Vietnam Family Study. I used the data of only married women who married between 1992 and $2000(\mathrm{~N}=989)$. Because I was interested in gender relations within the family, I selected currently married couples who lived together.

\section{Measures}

To compare married Vietnamese and Korean women, we selected comparable questions from each data source. I compared (a) the women's attitudes toward cohabitation, marriage, and divorce, (b) the women's attitudes toward having a child, (c) housework divisions, and (d) financial management. The original questions used in each study were summarized in <Table $1>$. Since each study was designed to collect data from its own people, each study used its own language, which was correspondingly Vietnamese or Korean. For international readers, the questions were translated into English.

In the Vietnam Family Study, respondents were asked to answer to what degree they agreed or 
Table 1. Survey Items in the 2003 Vietnam Family Study and the 2005 Korean National Marriage and Fertility Study

\begin{tabular}{|c|c|c|}
\hline Domains & 2003 Vietnam Family Study & 2005 Korean National Marriage and Fertility Study \\
\hline \multirow{3}{*}{$\begin{array}{l}\text { Marriage, Cohabitation, } \\
\text { and Divorce }\end{array}$} & $\begin{array}{l}\text { It Is Acceptable for Young Couples to Cohabit } \\
\text { Without Marriage. }\end{array}$ & $\begin{array}{l}\text { It is Ok for Young Couples to Cohabit Before } \\
\text { Marriage If They Plan to Marry. }\end{array}$ \\
\hline & $\begin{array}{l}\text { When A Couple Has Children, They Should Never } \\
\text { Divorce (Reverse Coding). }\end{array}$ & $\begin{array}{l}\text { It is Acceptable for A Couple to Divorce Even If } \\
\text { They Have Children. }\end{array}$ \\
\hline & $\begin{array}{l}\text { If A Couple is Unhappy Together, It is Acceptable } \\
\text { for Them to Divorce. }\end{array}$ & $\begin{array}{l}\text { If A Couple Can't Solve Marital Conflicts, It is } \\
\text { Better to Divorce. }\end{array}$ \\
\hline \multirow{3}{*}{ Child Value } & $\begin{array}{l}\text { Having Children is Important to Link The Ancestors, } \\
\text { The Living and Future Generations. }\end{array}$ & $\begin{array}{l}\text { A Couple Should Have A Child to Continue } \\
\text { Family Generations. }\end{array}$ \\
\hline & $\begin{array}{l}\text { It is Important to Have Children to Depend on When } \\
\text { You are Old }\end{array}$ & $\begin{array}{l}\text { People Can Rely on Children Financially When } \\
\text { They Get Older. }\end{array}$ \\
\hline & $\begin{array}{l}\text { Having Children is Important to Strengthen The } \\
\text { Bonds Between You and Your Spouse. }\end{array}$ & Children Strengthen The Bonds of Marriage. \\
\hline \multirow{11}{*}{$\begin{array}{l}\text { Household Division and } \\
\text { Decisions }\end{array}$} & Handling The Finances for Household Expenditures & Decisions Regarding Everyday Household Expenditures \\
\hline & Purchasing Expensive Goods & Purchasing A Home \\
\hline & Cooking & Household Work in General \\
\hline & Washing The Dishes & \\
\hline & Cleaning The House & \\
\hline & Doing The Laundry & \\
\hline & Looking After The Child & Child Care in General \\
\hline & Feeding & \\
\hline & Bathing & \\
\hline & Disciplining & \\
\hline & Playing & \\
\hline
\end{tabular}

disagreed on 11 items on cohabitation, marriage, divorce, and traditional gender roles on a 4-point Likert scale. Of the eleven statements, three items were selected because they were comparable to the questions from the Korean data. Respondents were also asked to answer how important it was to have children and given 4 items on a 4-point Likert scale. Of the four items, we selected three items for the same reason. Similarly, in the Korean Marriage and Fertility study, respondents were asked to answer to what degree they agreed or disagreed on items on cohabitation, marriage, divorce, and having children. Of the nine items on marriage and divorce, three items were selected. Of the eight items on having children, three items were selected. The answers were measured on a 4-point Likert scale. I compared the mean score of each item.

For financial management, I selected two questions from each data set. One question was about everyday household expenditures and the other question was about large expenditures. Both data sets adopted somewhat different questions. The Vietnam Family Study asked who handled most of the finances for household expenditures and who made the important decisions regarding the purchase of expensive goods. The Korean Marriage and Fertility Study asked who made the decisions regarding everyday household expenditures and who made the decisions regarding the purchase of a home (or a move). The intention underlying these questions was similar. The former question was about the management of everyday life resources and the latter was about the management of more important family resources.

For housework division, whereas the Vietnam Family Study used detailed questions, the Korean Marriage and Fertility Study used general questions. For example, the Vietnam Family Study asked who did most of the work and how much the respondents and their spouses contributed in each of 
buying food, cooking, washing the dishes, cleaning the house, and doing the laundry. In comparison, the Korean Marriage and Fertility Study asked how they and their spouses divided the overall housework (cooking, washing the dishes, doing the laundry, grocery shopping, and cleaning the house).

To compare family attitudes toward marriage, cohabitation, divorce, and child-rearing among married Vietnamese and Korean women, this study used t-test on each item. For all other comparisons, we compared descriptive figures by presenting percentages without applying statistical significance test. Because the survey measures varied, there was no straightforward way to apply significance test. Therefore, the results should be interpreted exploratory. All analysis was conducted using STATA 11.0.

\section{RESULTS}

\section{Marriage Characteristics of Respondents in Each} Country

First, this study compared the demographic characteristics of married couples between the two countries. This comparison provided a general description of the couples who married in 1992-2000 in each country. The average age of married Vietnamese women was 28.67 and the average age of married Korean women was 33. 45. This age difference resulted from different age at marriage. Vietnamese couples married at an earlier age than Korean couples. Specifically, Vietnamese men and women married at age 26.04 and at age 21.78 on averages, respectively, with a difference of 4.26 years between the man and woman. Korean men and women married at age 29.13 and at age 26.24 on averages, respectively, with a difference of 2.89 years between the man and woman. Korean men married at an age 3.09 years older than Vietnamese men. Korean women married at an age 4.6 years older than Vietnamese women. There was a larger age difference between the husband and wife in Vietnam than in Korea.

As expected, the educational level was higher for Koreans than Vietnamese. $57.6 \%$ and $38.1 \%$ of the
Table 2. Marriage Characteristics of Vietnamese and Korean Couples

\begin{tabular}{|c|c|c|}
\hline & $\begin{array}{l}2003 \text { Vietnam } \\
\text { Family Study } \\
\quad(\mathrm{N}=432)\end{array}$ & $\begin{array}{c}2005 \text { Korean Mar- } \\
\text { riage and Fertility } \\
\text { Study }(\mathrm{N}=989)\end{array}$ \\
\hline & $\begin{array}{l}\text { Means (S.D.) / } \\
\text { Percent }\end{array}$ & $\begin{array}{l}\text { Means (S.D.) / } \\
\text { Percent }\end{array}$ \\
\hline Age@Survey & $28.67(4.42)$ & $33.45(5.03)$ \\
\hline Age@Marriage & $21.78(3.51)$ & $26.24(4.86)$ \\
\hline Spouse Age@ Marriage & $26.04(4.47)$ & $29.13(5.25)$ \\
\hline \multicolumn{3}{|l|}{ Education } \\
\hline $\begin{array}{l}\text { Elementary School or } \\
\text { less }\end{array}$ & 15.31 & 2.17 \\
\hline Middle School & 47.81 & 2.06 \\
\hline High School & 26.72 & 57.63 \\
\hline College+ & 10.16 & 38.14 \\
\hline \multicolumn{3}{|l|}{ Spouse's Education } \\
\hline $\begin{array}{l}\text { Elementary School or } \\
\text { less }\end{array}$ & 12.70 & 1.33 \\
\hline Middle School & 43.89 & 1.94 \\
\hline High School & 30.25 & 46.78 \\
\hline College+ & 13.17 & 49.95 \\
\hline \multicolumn{3}{|l|}{ Number of Children } \\
\hline None & 9.03 & 0.00 \\
\hline One & 45.37 & 13.55 \\
\hline Two & 41.20 & 71.28 \\
\hline Three or More & 4.40 & 15.17 \\
\hline
\end{tabular}

Korean women graduated from high school and college, respectively. On the other hand, $26.7 \%$ and $10.2 \%$ of the Vietnamese women did so, respectively. Similarly, whereas $46.8 \%$ and $49.9 \%$ of the Korean men graduated from high school and college respectively, $30.3 \%$ and $13.2 \%$ of the Vietnamese men did so, respectively. The modal category for Vietnamese men and women was middle school graduation. In contrast, the modal category was high school graduation for Korean women and college graduation for Korean men. The tendency for husbands to have a higher educational level than wives existed in both countries.

The number of co-resident children was slightly larger for married Korean couples. Because the Vietnamese data were collected at an earlier time period of marriage, some of the Vietnamese couples had not completed their births at the time of the 
survey. While all of the Korean couples had at least one child, $9 \%$ of the Vietnamese couples had no children. In general, married Vietnamese couples had more children than Korean couples. Whereas the total fertility rate of Vietnam was 2.68 in 1994 and 2.09 in 2005 , the total fertility rate of Korea was 1.66 in 1996 and 1.13 in 2005 (UNPD, 2010).

\section{Family Attitudes of Married Women}

The first three questions in $<$ Table $3>$ were attitudes toward cohabitation, marriage, and divorce. The higher the score was, the less traditional the married woman's family attitudes were. The range of scores was from 1 (strongly disagree) to 4 (strongly agree). According to the t-test results, Vietnamese women agreed less with premarital cohabitation and with divorce if there were children than Korean women did. Interestingly, they agreed more with divorce due to an unhappy marriage than Korean women. Divorce was much less prevalent in Vietnam than in Korea: the crude divorce rate of Korea was ten times higher than that of Vietnam (UN Statistics Division, Demographic Yearbook 2008). However, the personal beliefs of married Vietnamese women reflected their preference for divorce over an unhappy marriage.

In our results, Vietnamese women considered children from both an instrumental and an emotional point of view. They agreed that having children was important because it was a way to link generations, to receive resources in old age, and to strengthen the marital bond. In comparison, Korean women viewed children less as a source of instrumental support or as a linkage of generations and more as a source of emotional value. They considered the existence of children to be beneficial for the marital relationship.

\section{Family Financial Management and Housework Division}

I used two measures to investigate gender roles in the family: financial management and housework division. While not perfect, identifying who took charge of family resources reflected gender relations and norms. I looked at both everyday household expenditures and expensive goods or homes purchases.

As seen in $<$ Table $4>$, Vietnamese and Korean families had similar patterns in managing everyday household expenditures. In both countries, over 70\% of the families responded that the wife managed the household expenditures. Only $4 \%$ of Vietnamese women and $7 \%$ of Korean women responded that the husband managed the money, and 15 19\% of the families said that both the husband and the wife equally managed the money. One difference was the proportion of others who managed everyday expenditures. While $7.6 \%$ of the Vietnamese families responded that everyday resources were managed by others, who were mostly husbands' parents (not shown). The proportion of others was negligible in Korean families.

There were some differences in the decisionmaking regarding more serious resource management. In Vietnamese families, such decisions were made equally $(45.9 \%)$ or by the husband $(31.4 \%)$.

Table 3. Family Attitudes of Married Vietnamese and Korean Women

\begin{tabular}{|c|c|c|c|}
\hline Items & $\begin{array}{c}\text { Vietnamese } \\
\text { women }(\mathrm{N}=431)\end{array}$ & $\begin{array}{l}\text { Korean women } \\
\quad(\mathrm{N}=988)\end{array}$ & $\mathrm{t}$ \\
\hline & Mean (S.D.) & Mean (S.D.) & \\
\hline It is Acceptable for Young Couples to Cohabit Without Marriage. & $1.29(.68)$ & $2.28(.88)$ & $20.55^{* * *}$ \\
\hline It is Acceptable For a Couple to Divorce Even If They Have Children. & $1.54(.78)$ & $2.33(.84)$ & $16.62 * * *$ \\
\hline If a Couple Is Unhappy Together, It is Acceptable for Them to Divorce. & $3.23(.83)$ & $2.48(.80)$ & $-16.02 * * *$ \\
\hline Having Children is Important to Link The Ancestors, the Living and Future Generations. & $3.42(.77)$ & $2.12(.78)$ & $-29.09 * * *$ \\
\hline It is Important to have Children to Depend on when You are Old & $3.20(.97)$ & $2.04(.63)$ & $-26.79 * * *$ \\
\hline Having Children is Important to Strengthen the Bonds Between You and Your Spouse. & $3.87(.37)$ & $3.64(.54)$ & $-8.10 * * *$ \\
\hline
\end{tabular}


Table 4. Financial Management of Married Vietnamese and Korean Women

\begin{tabular}{llcc}
\hline \multicolumn{1}{c}{ Finances } & By whom & $\begin{array}{c}\text { Vietnamese } \\
(\mathrm{N}=433)\end{array}$ & $\begin{array}{c}\text { Korean } \\
(\mathrm{N}=988)\end{array}$ \\
\hline & & Percent & Percent \\
\hline Keeping Money for Household Expenditures (Vietnam) & Husband & 3.70 & 7.28 \\
Decision-making Regarding Everyday Household Expenditures (Korea) & Wife & 74.13 & 73.21 \\
& Equally & 14.55 & 18.71 \\
& Others & 7.62 & 0.40 \\
\hline Purchase of expensive goods (Vietnam) & Husband & 31.41 & 10.11 \\
Purchase of a home (Korea) & Wife & 12.47 & 11.02 \\
& Equally & 45.96 & 77.25 \\
& Others & 10.16 & 1.11 \\
\hline
\end{tabular}

Table 5. Household Work Division of Married Couples in Vietnam and Korea

\begin{tabular}{lcccc}
\hline & Husband & Wife & Equally & Others \\
\hline & Percent & Percent & Percent & Percent \\
\hline Vietnam (N=433) & & & & \\
Buying Food & 1.39 & 85.91 & 3.00 & 9.70 \\
Cooking & 1.62 & 85.91 & 4.85 & 7.62 \\
Washing the Dishes & 0.92 & 88.68 & 3.23 & 7.16 \\
Cleaning the House & 2.08 & 83.83 & 7.39 & 6.70 \\
Doing the Laundry & 2.08 & 88.22 & 4.62 & 5.08 \\
\hline Looking after the Child 2-5 & 0.75 & 72.00 & 6.75 & 20.50 \\
Disciplining the Child 2-5 & 8.75 & 52.75 & 33.00 & 5.50 \\
Playing with the Child 2-5 & 2.75 & 52.50 & 29.75 & 15.00 \\
Helping the Child with Homework 6-10 & 18.80 & 58.40 & 18.40 & 4.40 \\
Disciplining the Child 6-10 & 20.00 & 36.40 & 39.20 & 4.40 \\
\hline Korea (N=988) & & & & \\
Overall Housework & 0.71 & 78.87 & 16.99 & 0.40 \\
Overall Child Care Under 12 & 1.92 & 63.40 & 31.55 & 0.40 \\
\hline
\end{tabular}

Note: The number of respondents varies according to the questions. Four hundred Vietnamese women responded to the questions about child 2-5 and two hundred fifty Vietnamese women responded to the questions about child 6-10.

About $12.5 \%$ of the wives were solely responsible for making decisions regarding the purchase of expensive goods. In Korean families, decision-making regarding the purchase of a home was, for the most part, made equally (77.3\%). One-tenth of the families responded that the decisions were made solely by the husband, and another tenth responded that the decisions were made solely by the wife. In sum, there was similarity between the two countries in that the wives were responsible for everyday household expenditures. But when it came to more serious financial decisions, Vietnamese husbands tended to have more influence than Korean husbands.

It is somewhat difficult to directly compare the patterns of housework division between the two countries because they adopted different approaches of measurement. Still, some patterns were identified. 
As presented in $<$ Table $5>$, regardless of the type of housework, about $85 \sim 90 \%$ of the families responded that the work was done by the wife in Vietnamese families. The proportion of families in which the husband was mainly responsible for the housework is less than $3 \%$. In about 3 7\% of the families, there was an equal division of household chores between the husband and wife. Similarly, about $80 \%$ of the Korean respondents said the work was done by the wife. The proportion of the respondents who said that there was an equal division of housework between the husband and the wife was $17 \%$ in Korea, which was much larger than in Vietnam.

The patterns of participating in child-rearing were somewhat different between the two countries. While there was a similarity in that the mother took the major responsibility in caring for the children, the father's participation was more prevalent in Vietnam than in Korea. The mother took sole responsibility of child care in six of every ten Korean families. About $32 \%$ of the families responded that the parents shared the responsibility. There were a few families in which the father took sole responsibility. However, a larger proportion of Vietnamese fathers took sole responsibility in helping homework or disciplining children. About $9 \%$ of families with children aged 2 to 5 and $20 \%$ of families with children aged 6 to 10 had fathers who mainly disciplined their children. Combined with the proportions of shared responsibility, Vietnamese fathers were involved more in child discipline and education than Korean fathers. In Vietnam, a significant proportion of the married couples with young children under the age of 6 appeared to receive help from other relatives (again, mostly from husband's parents, not shown). In comparison, such help was not found in Korean families.

\section{CONCLUSIONS}

This study examined similarities and differences in family attitudes and gender role divisions within the family in contemporary Vietnam and Korea. While there has been increasing interest and interactions between the two countries, there was little empirical research done from a comparative perspective. Such research is important due to the growth in international marriages between Korean men and Vietnamese women and to the increasing interests in Southeast Asian countries.

The results showed that married Vietnamese women seemed to accept more traditional family norms than married Korean women. Married Vietnamese women agreed less with cohabitation and divorce when there were children than Korean women did. In terms of having children, married Vietnamese women agreed more with the instrumental value of children than Korean women. Vietnamese women viewed children as a mean of linking generations and serving ancestors. They also expected that children would help aging parents financially. Married Korean women were less inclined toward these perceptions.

In both countries, everyday household expenditures were managed by the wife. However, regarding more serious decisions, such as the purchase of expensive goods or a home, married Vietnamese men had more decision-making power than married Korean men. In terms of household work, most household work was done by the wife. Yet, the proportion of equal household work was higher in Korean families than in Vietnamese families. Finally, while wives had primary responsibility of child care and education in both countries, Vietnamese husbands played an important part in child discipline and education than Korean husbands. It was identical that married women took main responsibilities and duties in household work and management in the two countries. Yet, the level of husband's involvement or the level of shared responsibility on serious family resource management and child education and discipline differed.

The overall findings implied that traditional family norms were stronger and male household heads had more decision-power in Vietnam than in Korea. Traditional family norms under the Confucianism influence subscribe the authority of household head. The household head controls the family property, supervises the activities and behavior of the family members, and represents the family to the outside world (Lee, 1997). These 
traditional family norms make husbands take major responsibility for and involve more in family resource management and child education. While married Vietnamese men did not share equal amount of household work, they seemed to engage more in children's education and important family decisions as a main figure. In comparison, while married Korean men participated more in household work equally, they did not voice solely for family matters. There was a distance from traditional Confucian family norms in that more equitable gender role divisions presented in Korean families.

These results provide some implications for intercultural marriage between Korean men and Vietnamese women. Vietnamese women place values on stable marriages and having children than Korean women. Consequently, they might be more vulnerable for actual or potential threats of marital dissolution. This tendency places them to an inferior status within family. In addition, the results show that Korean husband and Vietnamese wife may have different expectations for husband's and wife's role. For example, Vietnamese wife expects the husband to take more responsibility for children's education and financial management. However, Korean husband regards children's education as a main responsibility of wife. This incongruence may create marital conflicts. Not only the couple themselves but also professionals should acknowledge these cultural differences in family attitudes and gender role divisions. To assist these intercultural married couples, family life education taking these cultural differences into consideration needs to be provided at Healthy Family Support Centers or Multi-cultural Family Support Centers.

Finally, there are several limitations in this study. First, this study did not use perfectly matching data sets. The two data sets drawn were collected in different time points with limited range of survey questions. These data were not comprehensive enough to manifest general family attitudes and gender relations in family and could not allow significance tests with a range of control variables. Furthermore, the Vietnam data contained younger married women than the Korean data. The results found in this study, therefore, may be attributed partly to the age differences of the two groups. Second, this study drew information from general population of the married women in both countries. If Vietnamese women who came to Korea for marriage had different backgrounds from the general married women in Vietnam, they might have had different family and gender role attitudes. Lastly, this study reveals some differences in family attitudes and gender role divisions within family but does not attempt to explain the reasons for these differences. There must be a wide range of differences between Vietnam and Korea such as the level of modernization, political-economic systems, average educational level of men and women and many other demographic or socio-economic conditions. It is beyond the scope of this study to examine each source of explanation, however. It also needs to be acknowledged that both Korea and Vietnam are rapidly changing countries. Family and gender role norms can change according to societal changes. Thus, the tendency found in this study should be interpreted in the specific time frame. Since this study used data collected in 2003 for Vietnam and 2005 for Korea, it should be noted that this may not be the most current pictures of the two countries. Notwithstanding these limitations, this study adds to the family studies literature based on the empirical findings with a comparative perspective. In future research, more comparable data need to be collected from both countries and more elaborate analysis techniques needs to be incorporated.

\section{REFERENCES}

Belanger, D., Oanh, K.T.H., Kuanye, L., Thuy, L. T., \& Thank, P. V. (2003). Are sex ratios at birth increasing in Vietnam? Population, 58(2), 231-250.

Bryant, J. (2002). Patrilines, patrilocality and fertility decline in Vietnam. Asia-Pacific Population Journal, 17(2), 111-128.

Chang, K. (2010). Individualization without individualism: Compressed modernity and obfuscated family crisis in East Asia. Journal of Intimate and Public Spheres: Asian and Global Forum, Pilot Issue, 23-39. 
CIA (2010). World fact book, 2010.

Hirschman, C., \& Loi, V. M. (1996). Family and household structure in Vietnam: Some glimpses from a recent survey. Pacific Affairs, 6(1), 229-249.

Jayakody, R., \& Huy V. T. (2008). Social change and marriage in Vietnam: From socialist state to market reform. In R. Jayakody, A. Thorton., \& W. Axinn (Eds.) International family change: Ideational perspectives. Lawrence Erlbaum Associates.

Kim, J. (2002). Family and household. In Kim, D., Park, S., \& Eun, K. (Eds.), Population of Korea. Korea National Statistical Office.

Korea Statistics Office (2011). Marriage Statistics.

Korea Statistics Office (2011). Population and Housing Census.

Lee, K. (1997). Korean family and kinship. Korean Studies Series No. 3. Seoul: Jipmoondang Publishing Company.

Lee, J., Katras, M. J., \& Bauer, J. W. (2010). Values underlying U.S. low-income rural mothers' voices about welfare and welfare reform: An inductive analysis. International Journal of Human Ecology, 11, 63-75.

Nguyen-Dinh, H. (1997). A Socioeconomic analysis of the determinants of fertility: The case of Vietnam.
Journal of Population Economics, 10, 251-271.

Piper, N. (2003). Wife or worker? worker or wife? Marriage and cross-border migration in contemporary Japan. International Journal of Population Geography, 9, 457-469.

United Nations, Department of Economic and Social Affairs, Population Division, World Fertility Data 2008. Period fertility indicators. Retrieved from http:// www.un.org/esa/pplation/publications/WFD\%202008/ Main.html.

United Nations, Department of Economic and Social Affairs, Statistics Division, Demographic yearbook 2008. Retrieved from http://unstats.un.or/unsd/ demographic/products/dyb/dyb2008.htm.

Whitmore, J. K. (1984). Social organization and Confucian thought in Vietnam. Journal of Southeast Asian Studies, 15(2), 296-306.

$\mathrm{Yu}$, I. (1997). Acceptance and transformation of Chinese family institution in pre-modern Vietnam. The Southeast Asian Review, 5, 25-50.

Received October 12, 2011

Revised November 14, 2011

Accepted December 5, 2011 